\title{
Cue-Evoked Cocaine "Craving": Role of Dopamine in the Accumbens Core
}

\author{
Benjamin T. Saunders, Lindsay M. Yager, and Terry E. Robinson \\ Biopsychology Program, Department of Psychology, University of Michigan, Ann Arbor, Michigan 48109
}

\begin{abstract}
Drug-associated cues can acquire powerful motivational control over the behavior of addicts, and can contribute to relapse via multiple, dissociable mechanisms. Most preclinical models of relapse focus on only one of these mechanisms: the ability of drug cues to reinforce drug-seeking actions following a period of extinction training. However, in addicts, drug cues typically do not follow seeking actions; they precede them. They often produce relapse by evoking a conditioned motivational state ("wanting" or "craving") that instigates and/or invigorates drug-seeking behavior. Here we used a conflict-based relapse model to ask whether individual variation in the propensity to attribute incentive salience to reward cues predicts variation in the ability of a cocaine cue to produce conditioned motivation (craving) for cocaine. Following self-administration training, responding was curtailed by requiring rats to cross an electrified floor to take cocaine. The subsequent response-independent presentation of a cocaine-associated cue was sufficient to reinstate drug-seeking behavior, despite the continued presence of the adverse consequence. Importantly, there were large individual differences in the motivational properties of the cocaine cue, which were predicted by variation in the propensity to attribute incentive salience to a food cue. Finally, a dopamine antagonist injected into the nucleus accumbens core attenuated, and amphetamine facilitated, cue-evoked cocaine seeking, implicating dopamine signaling in cocaine cue-evoked craving. These data provide a promising preclinical approach for studying sources of individual variation in susceptibility to relapse due to conditioned craving and implicate mesolimbic dopamine in this process.
\end{abstract}

\section{Introduction}

Cues associated with drug use can acquire powerful control over motivated behavior, contributing to high rates of relapse, via three related but dissociable mechanisms (Cardinal et al., 2002; Milton and Everitt, 2010). First, cues can become attractive and attention grabbing, eliciting approach toward them. Second, they become desirable in their own right, acting as conditioned reinforcers. Third, and perhaps most important for relapse, they can evoke powerful conditioned motivational states ("wanting" or "craving") capable of spurring new drug-seeking actions or invigorating ongoing ones, even in the face of adverse consequences (Stewart et al., 1984; Robinson and Berridge, 1993; Milton and Everitt, 2010).

In preclinical studies, the ability of drug cues to serve as conditioned reinforcers has received considerable attention. Indeed, in most so-called "cue-induced" reinstatement studies, the drug cue does not actually induce behavior but serves to reinforce actions already taken (Shaham et al., 2003; Epstein et al., 2006;

Received Jan. 30, 2013; revised July 2, 2013; accepted July 20, 2013.

Author contributions: B.T.S. and T.E.R. designed research; B.T.S. and L.M.Y. performed research; B.T.S. and T.E.R. analyzed data; B.T.S., L.M.Y., and T.E.R. wrote the paper.

This research was supported by grants from the National Institute on Drug Abuse to B.T.S. (F31 DA030801), L.M.Y. (F31 DA030799), and T.E.R. (P01 DA031656). The content is solely the responsibility of the authors and does not necessarily represent the official views of the National Institute on Drug Abuse or the National Institutes of Health. We thank Elizabeth $0^{\prime}$ Donnell and Ethan Kolderman for assistance with behavioral testing.

Correspondence should be addressed to Dr. Terry E. Robinson, Department of Psychology, University of Michigan, 530 Church Street, East Hall, Ann Arbor, MI 48109. E-mail: ter@umich.edu.

B.T. Saunders' present address: Center for Integrative Neuroscience, University of California, San Francisco, San Francisco, CA 94143.

DOI:10.1523/JNEUROSCI.0450-13.2013

Copyright $\odot 2013$ the authors $\quad 0270-6474 / 13 / 3313989-12 \$ 15.00 / 0$
Bossert et al., 2013). In addicts, however, drug cues most often precede drug-seeking actions-they instigate such actions, by arousing a conditioned motivational state (Bindra, 1978; Stewart et al., 1984). This can influence behavior implicitly ("craving"; Fischman, 1989; Fischman and Foltin, 1992; Robinson and Berridge, 1993; Childress et al., 2008), or if cue-evoked conditioned motivation reaches the level of conscious awareness, it is experienced as a strong urge or desire (craving), the intensity of which can predict future drug intake and the likelihood of relapse (Ehrman et al., 1992; Carter and Tiffany, 1999; Preston et al., 2009).

It is difficult to examine drug cue-evoked conditioned motivation in preclinical studies, because craving can only be indirectly measured. Pavlovian-to-instrumental transfer (PIT) procedures (Estes, 1943, 1948; Lovibond, 1983) have been used to infer conditioned motivation for food cues, but, until recently, none have demonstrated such an effect with drug cues. LeBlanc et al. (2012), using a PIT paradigm, successfully demonstrated that the noncontingent presentation of a cocaine cue can invigorate ongoing self-administration behavior (also see Corbit and Janak, 2007). However, attempts to model conditioned motivational mechanisms of relapse in rats, via the response-independent presentation of drug cues, have been relatively unsuccessful (de Wit and Stewart, 1981; Grimm et al., 2000; Deroche-Gamonet et al., 2002; but see Barker et al., 2012). To address this issue, we used a conflict-based relapse model developed by Cooper et al. (2007) to assess the ability of a cocaine cue to produce conditioned craving, quantified by its ability to spur drug-seeking behavior in the face of an adverse consequence. We were especially interested in whether individual variation in susceptibility to relapse in this 
situation (Cooper et al., 2007; Barnea-Ygael et al., 2012; Peck et al., 2013) is predicted by individual variation in the propensity to attribute incentive salience to reward cues (Flagel et al., 2009; Saunders and Robinson, 2013). Finally, we manipulated dopamine signaling within the nucleus accumbens core (Ikemoto and Panksepp, 1999; Cardinal et al., 2002) during conflict reinstatement, because it is unknown whether dopamine is necessary specifically for cocaine cue-evoked conditioned motivation.

\section{Materials and Methods Subjects}

Male Sprague Dawley rats $(N=100$; Harlan) weighing 275-325 g at surgery were individually housed in a temperature- and humiditycontrolled colony room on a $12 \mathrm{~h}$ light/dark cycle (lights on at 8:00 A.M.). Water and food were available ad libitum (i.e., rats were not food deprived at any time). After arrival, rats were given 1 week to acclimate to the colony room before any testing began, during which time the experimenter handled them several times. All procedures were approved by the University of Michigan Committee on the Use and Care of Animals.

\begin{abstract}
Apparatus
Behavioral testing was conducted in standard $(30.5 \times 24.1 \times 21 \mathrm{~cm})$ test chambers (Med Associates) located inside sound-attenuating cabinets. A ventilating fan masked background noise. For pavlovian training, each chamber had a food cup located in the center of one wall, $3 \mathrm{~cm}$ above a stainless steel grid floor. Head entries into the food cup were recorded by breaks of an infrared photobeam located inside. A retractable lever that could be illuminated from behind was located $2.5 \mathrm{~cm}$ to the left or right of the food cup, $\sim 6 \mathrm{~cm}$ above the floor. The location of the lever with respect to the food cup was counterbalanced across rats. On the wall opposite the food cup, a red house light remained illuminated throughout all experimental sessions. Responses were recorded using Med Associates software.
\end{abstract}

\section{Surgery}

Following pavlovian training, rats were prepared with intravenous catheters as described previously (Crombag et al., 2000) under ketamine hydrochloride (100 mg/kg, i.p.) and xylazine (10 mg/kg, i.p.) anesthesia. Following surgery, catheters were flushed daily with $0.2 \mathrm{ml}$ of sterile saline containing $5 \mathrm{mg} / \mathrm{ml}$ gentamicin sulfate (Vedco) to minimize infection and prevent occlusions. Catheter patency was tested at the end of testing by intravenous injection of $0.2 \mathrm{ml}$ of methohexital sodium (10 $\mathrm{mg} / \mathrm{ml}$ in sterile water; JHP Pharmaceuticals). Only rats that became ataxic within 5-10 s were considered to have patent catheters and were included in the analyses. For Experiment 2, after receiving an intravenous catheter, rats were positioned in a stereotaxic apparatus (David Kopf Instruments). The skull of each rat was leveled, and chronic guide cannulae (22 gauge stainless steel; Plastics One) were inserted bilaterally 2 $\mathrm{mm}$ above the target site in the nucleus accumbens core (relative to bregma: anterior $+1.8 \mathrm{~mm}$; lateral $+1.6 \mathrm{~mm}$; ventral $-5.0 \mathrm{~mm}$ ). Guide cannulae were secured with skull screws and acrylic cement, and wire stylets (28 gauge; Plastics One) were inserted to prevent occlusion. After surgery, all rats received antibiotic and carprofen $(5 \mathrm{mg} / \mathrm{kg})$ for pain. Rats were allowed to recover from surgery for at least $7 \mathrm{~d}$ before testing began.

\section{Microinjections}

In Experiment 2, before the reinstatement test session, rats received a single microinjection of vehicle ( $0.9 \%$ sterile saline); flupenthixol $(20 \mu \mathrm{g}$ in saline, weight of the salt; Sigma), a relatively nonselective dopamine receptor antagonist; or D-amphetamine sulfate ( $10 \mu \mathrm{g}$ in saline, weight of the salt; Sigma), an indirect agonist. Drug doses were based on those used in previous studies, for which flupenthixol has no nonspecific effects on locomotion (Wyvell and Berridge, 2000; Di Ciano et al., 2001; Ito and Hayen, 2011; Saunders and Robinson, 2012). We should note here that our goal with these studies was not to establish a broad pharmacological profile of "sign tracker" (ST)/"goal tracker" (GT) sensitivity to flupenthixol and amphetamine, which would require replicating these studies across a variety of drug doses, but instead to examine the effect of dopamine manipulations, generally, on cue-evoked relapse. Such detailed pharmacological studies, and potentially others assessing the potential dopamine receptor specificity of these effects, will be important avenues of future research.

Intracerebral microinjections were made through 28 gauge injector cannulae (Plastics One) lowered to the injection site in the nucleus accumbens core (ventral $-7.0 \mathrm{~mm}$, relative to skull), $2 \mathrm{~mm}$ below the ventral tip of the guide cannulae. During infusions, rats were gently held by the experimenter. All infusions were administered bilaterally at a volume of $0.5 \mu \mathrm{l} /$ side, delivered over $90 \mathrm{~s}$ using a syringe pump (Harvard Apparatus) connected to microinjection cannulae via PE-20 tubing. After infusions, the injectors were left in place for $60 \mathrm{~s}$ to allow for drug diffusion before being withdrawn and replaced with wire stylets. Rats received a microinjection of saline $\sim 5 \mathrm{~d}$ before the reinstatement test, to acclimate them to the injection procedure.

\section{Procedures}

\section{Experiment 1: individual variation in cocaine} cue-evoked reinstatement

Pavlovian training. Pavlovian training procedures were similar to those described previously (Flagel et al., 2007; Saunders and Robinson, 2010). For $2 \mathrm{~d}$ before the start of training, 10 banana-flavored pellets ( $45 \mathrm{mg}$; catalog \#F0059, BioServe) were placed in the home cage to familiarize the rats with this food. Approximately 1 week after arrival, rats were placed in the test chambers, with the lever retracted, and trained to retrieve pellets from the food cup by receiving $2545 \mathrm{mg}$ banana pellets on a variable time (VT) $30 \mathrm{~s}$ schedule. All rats retrieved the pellets and began pavlovian training the next day. Each trial consisted of insertion (and simultaneous illumination) of the lever [conditional stimulus (CS)] into the chamber for $8 \mathrm{~s}$, after which time the lever was retracted and a single food pellet [unconditional stimulus (US)] was immediately delivered into the adjacent food cup. Each training session consisted of 25 trials in which CS-US pairings occurred on a VT $90 \mathrm{~s}$ schedule (the time between CS presentations varied randomly between 30 and 150 s). Lever deflections, food cup entries during the $8 \mathrm{~s}$ CS period, latency to the first lever deflection, latency to first food cup entry during the CS period, and food cup entries during the intertrial interval were measured.

Quantification of behavior using an index of pavlovian conditioned approach. For some analyses, rats were classed into three groups: (1) those that preferentially interacted with the lever (STs); (2) those that preferentially interacted with the food cup during lever presentation (GTs); and (3) those that had no clear preference for the lever or food cup ["intermediates" (INs)]. The extent to which behavior was lever (CS) or food-cup directed was quantified using a composite index (Lovic et al., 2011; Saunders and Robinson, 2011; Meyer et al., 2012) that incorporated three measures of the pavlovian conditioned approach (PCA): (1) the probability of either deflecting the lever or entering the food cup during each CS period [ $p$ value (lever) $-p$ value (food cup)]; (2) the response bias for contacting the lever or the food cup during each CS period [(number of lever deflections - number of food-cup entries)/ (number of lever deflections + number of food-cup entries)]; and (3) the latency to contact the lever or the food cup during the CS period [(lever deflection latency - food-cup entry latency)/8]. Thus, the PCA index score consisted of (probability difference score + responses bias score + latency difference score)/3. This formula produces values on a scale ranging from -1.0 to 1.0 , where scores approaching -1.0 represent a strong food cup-directed bias and scores approaching 1.0 represent strong lever-directed bias. The average PCA index score for days 4 and 5 of training was used to place rats in a class. Rats were designated as STs if they obtained an average index score of 0.25 or greater, and as GTs if they obtained a score of -0.25 or less. The remaining rats within the -0.24 to 0.24 range were classed as INs.

Self-administration: acquisition. Self-administration sessions began 1 week after surgery in chambers outfitted with two nose ports, but no lever or food magazine. A nose poke into the active port resulted in an intravenous injection of cocaine $\mathrm{HCl}(0.4 \mathrm{mg} / \mathrm{kg}$ per infusion, weight of the salt) in $50 \mu \mathrm{l}$ of saline delivered over $2.6 \mathrm{~s}$ on a fixed ratio 1 schedule. Coincident with the start of an infusion was a $20 \mathrm{~s}$ timeout period, during 


\section{A}

\section{Traditional Extinction-Reinstatement Procedure}

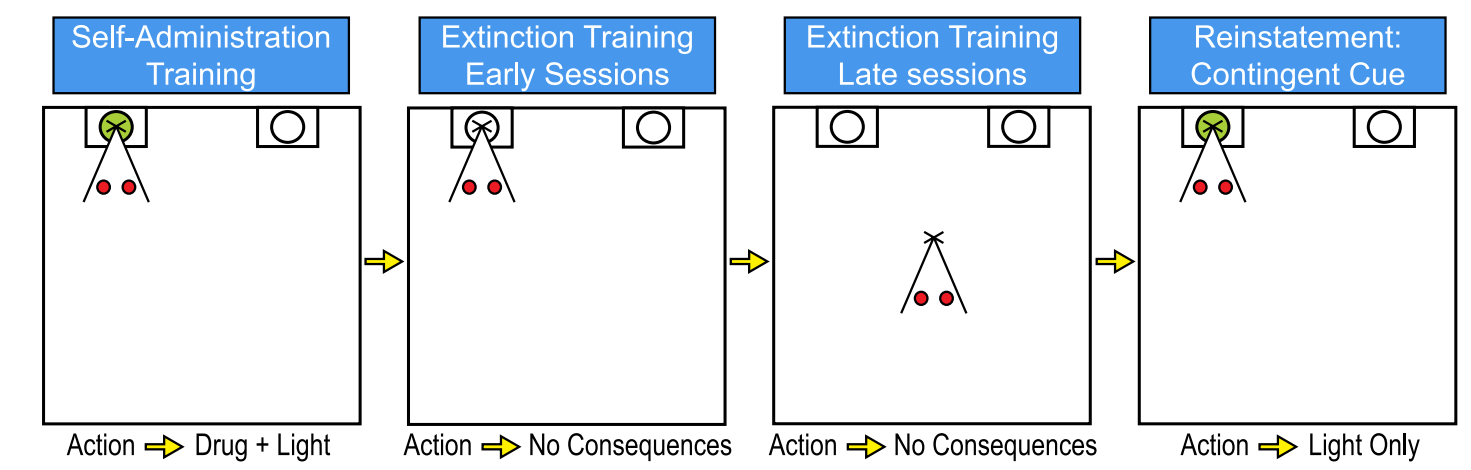

\section{B}

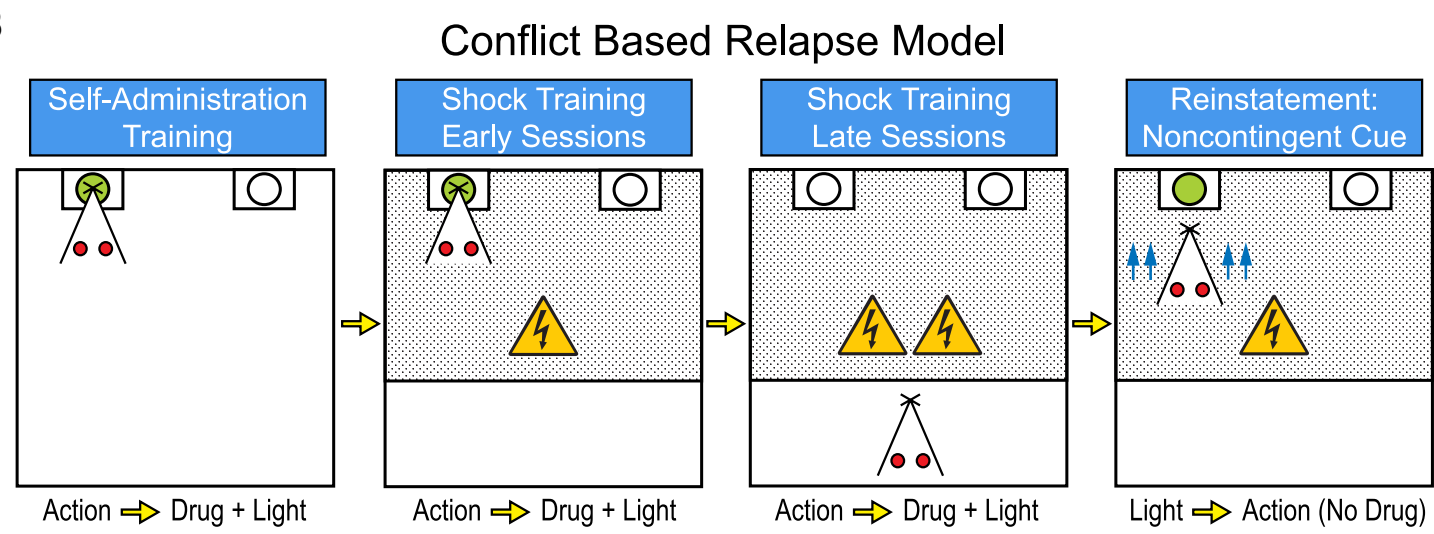

Figure 1. Diagram comparing reinstatement procedures. $A$, Traditional extinction-reinstatement procedure. Typically in these studies, rats are trained to self-administer cocaine paired with a discrete visual cue (left). Following acquisition of stable self-administration, extinction training commences, where actions have no consequences. Rats initially respond at a high rate (second panel), but eventually learn that cocaine is no longer available and stop responding (third panel). During the reinstatement test, drug-seeking actions produce the cocaine-paired cue only (right), which promotes a new high level of responding. $\boldsymbol{B}$, Conflict-based relapse model. Rats are first trained to self-administer cocaine paired with a discrete visual cue, as in $\boldsymbol{A}$ (left). Following the acquisition of stable self-administration, the front two-thirds of the chamber floor is electrified with constant current. Initially, footshock is applied at a low intensity, and rats continue to self-administer cocaine (second panel). Footshock intensity is then gradually escalated, resulting in a near-complete discontinuation of cocaine self-administration (third panel) despite continued drug availability. During the reinstatement test, the cocaine-paired cue is presented intermittently throughout the session and independent of the animal's behavior. The ability of the cue to spur a rat to cross the electrified floor to make drug-seeking responses, which now have no consequences, is quantified (right). This conflict procedure was based on Cooper et al. (2007), although in that study an action also produced the cue (i.e., the cue could also act as a conditioned reinforcer), which was not the case here.

which nose pokes had no consequences. For some rats (PAIRED groups), this timeout coincided with illumination of the cue light inside the nose port for $20 \mathrm{~s}$. Thus for PAIRED rats, this light served as the CS signaling cocaine delivery. For other rats (UNPAIRED control group, $n=30$ ), the nose port cue light was not explicitly paired with cocaine delivery. For these rats (UNPAIRED groups), the cue light was presented in a "truly random" fashion (Rescorla, 1967; Bertz and Woods, 2013), regardless of behavior, on a variable interval schedule of $180 \mathrm{~s}$ (i.e., the cue was presented on average every $180 \mathrm{~s}$, with a range of 60-300 s). These UNPAIRED control groups were included to establish that any subsequent reinstatement behavior (see below) was dependent on the contingency between the cue and cocaine (Rescorla, 1967). For PAIRED and UNPAIRED groups, we used a training procedure guaranteeing that all rats received exactly the same number of cocaine injections and cue presentations, by imposing an infusion criterion (IC) on self-administration sessions (Saunders and Robinson, 2010,2011; i.e., session length was determined by how long it took each rat to reach the IC, not by an explicit time limit). Rats were initially allowed to take 10 infusions per session for three sessions, and this IC was then increased to 20 for three sessions and finally to 40 infusions for five sessions. For UNPAIRED groups, the number of cue presentations was matched to each IC.

Imposition of an adverse consequence to drug self-administration. In most reinstatement studies (for review, see Shaham et al., 2003; Bossert et al., 2013; Marchant et al., 2013), following the acquisition of selfadministration animals undergo extinction training to reduce behavior to a low level before a reinstatement test (Fig. 1A). However, we wanted to avoid extinction training, for two reasons. One, addicts typically do not undergo extinction training before relapse, but may be abstinent for a number of reasons, including adverse consequences of continued drug use. Two, extinction training itself has significant effects on brain and behavior (Knackstedt et al., 2010). Therefore, we used a conflict-based relapse model developed by Cooper et al. (2007 (see also Barnea-Ygael et al., 2012; Peck et al., 2013), where an aversive consequence (footshock) is imposed on drug taking, and gradually escalated until drug taking reaches near-abstinence levels (Fig. $1 B$ ). During this phase, after the acquisition of stable cocaine self-administration behavior, sessions were no longer determined by the number of infusions, but instead were limited to $30 \mathrm{~min} / \mathrm{d}$. Electric current was constantly applied to the front twothirds of the chamber floor throughout these sessions, such that rats were required to walk across the electrified portion of the floor to make a nose poke and receive a cocaine infusion, which remained paired with the cocaine cue for PAIRED groups. For UNPAIRED groups, the cue light was presented randomly between 60 and $180 \mathrm{~s}$ after each cocaine infusion, and the number of cue presentations was matched to each rat's cocaine intake. Thus, in contrast to extinction training, drug remained available at all times, but rats were faced with a choice of whether or not to continue taking cocaine in the face of rising negative consequences (Fig. 1). We should also note that this procedure is different from socalled "punishment-induced abstinence" procedures, where brief footshocks are administered following a drug-taking response (Pelloux et al., 2007). Initially, rats received a $30 \mathrm{~min}$ session with footshock set at $0 \mathrm{~mA}$, to establish baseline levels of behavior, followed by successive sessions 
with footshock set at $0.15,0.20$, and $0.25 \mathrm{~mA}$. At this point, any rats that took fewer than five cocaine infusions received one additional session with the same shock intensity. For any rats that took more than five infusions, the footshock intensity was increased in subsequent sessions by increments of $0.05 \mathrm{~mA}$, until they took fewer than five infusions. Following this adverse-consequences training phase, rats were returned to their home cages for a 2 week "incubation period" (Grimm et al., 2001) before the reinstatement test.

Reinstatement. After the incubation period, rats were returned to the self-administration chambers for a $30 \mathrm{~min}$ reinstatement test under extinction conditions (no drug available). Importantly, during this session, the front two-thirds of the chamber floor remained electrified, as before, but at $50 \%$ of the intensity each rat had reached at the end of shock training. Additionally, for both PAIRED and UNPAIRED groups, the cocaine-associated cue light was illuminated noncontingently, that is, independent of the rat's behavior, for $20 \mathrm{~s}$ every 3 min (thus, in this test, nose pokes did not produce the cue). This was done to isolate the ability of the cocaine cue to evoke drugseeking behavior (to "goad actions"; Stewart et al., 1984) from its ability to reinforce actions already emitted.

Finally, as another control, an independent group of STs $(n=7)$ was treated identically to the PAIRED rats described above, except that during the reinstatement session no cue was presented. This group was included to determine whether mere re-exposure to the test chamber, after 2 weeks of abstinence, and with the shock intensity half of what it was on the last day of training, was sufficient to produce robust reinstatement in STs.

Experiment 2: the role of nucleus accumbens core dopamine in cocaine cue-evoked reinstatement

A separate cohort of rats was used in Experiment $2(n=43)$. All behavioral procedures leading up to the reinstatement session were identical to the PAIRED groups in Experiment 1.

Reinstatement. Following the incubation period, STs and GTs were assigned to one of three drug treatment groups [vehicle (VEH; saline), flupenthixol (FLU), or amphetamine (AMPH)], for a total of six independent groups: ST-VEH $(n=8)$, ST-FLU $(n=8)$, ST-AMPH $(n=7)$, GT-VEH $(n=6)$, GT-FLU $(n=7)$, and GT-AMPH $(n=7)$. On the day of the reinstatement test, each rat received a single microinjection, as described above, before being placed in the test chamber 10-15 min later. Reinstatement session parameters, including noncontingent cue presentations, were identical to Experiment 1.

Histology. After the completion of behavioral testing, rats in Experiment 2 were anesthetized with an overdose of sodium pentobarbital, and their brains were removed and flash frozen in isopentane chilled to approximately $-30^{\circ} \mathrm{C}$ by a mixture of isopropyl alcohol and dry ice. Frozen brains were sectioned on a cryostat at a thickness of $60 \mu \mathrm{m}$, mounted on slides, air dried, and stained with cresyl violet. Microinjection sites were verified by light microscopy and plotted onto drawings from a rat brain atlas (Paxinos and Watson, 2007).

Data analyses. We were primarily interested in a comparison of the ability of the cocaine cue to reinstate drug-seeking behavior in rats that were prone to attribute incentive salience to a food cue (STs), relative to those less prone to do so (GTs). Therefore, in Experiment 1, the INs were excluded for group comparisons. However, for correlational analyses to assess whether variation in the PCA index score predicted cocaine cueinduced reinstatement behavior, all animals were included (STs, GTs, and INs). INs were not used in Experiment 2, so those analyses only include STs and GTs.

Linear mixed-model ANOVAs were used for all repeated-measures data. The best-fitting model of repeated-measures covariance was determined by the lowest Akaike information criterion score (Verbeke, 2009). Depending on the model selected, the degrees of freedom may have been adjusted to a noninteger value. Two-way (group: ST/GT by nose poke: active/inactive) ANOVAs were used to compare groups during reinstatement tests. The $t$ test was used for planned comparisons of group means. In Experiment 1, Pearson's correlations were used to determine the strength of the relationship between PCA index scores and active re-

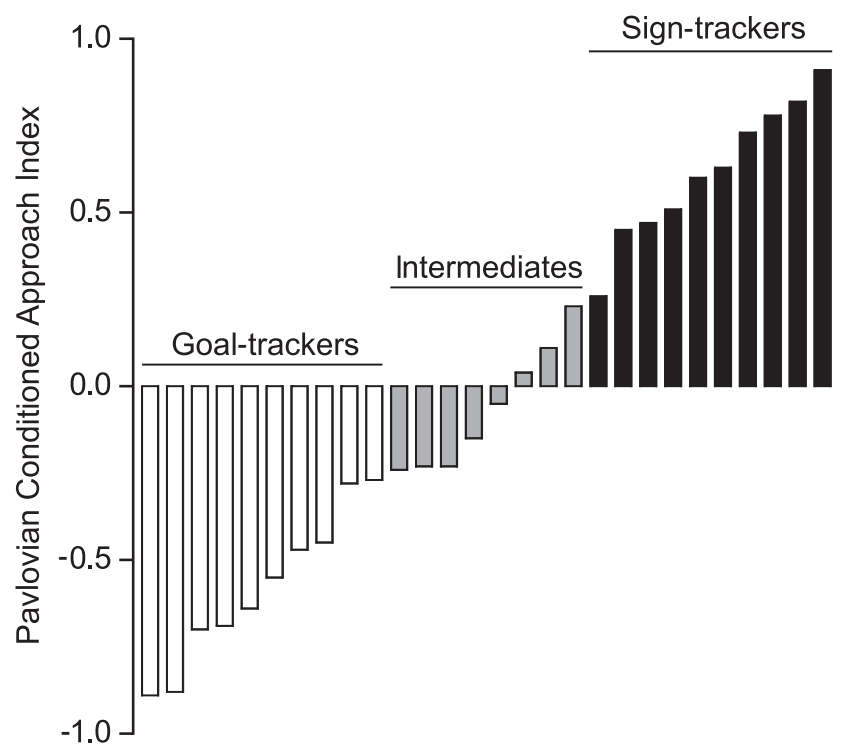

Figure 2. Individual variation in PCA behavior. PCA index scores for individual rats from the PAIRED groups in Experiment 1 were calculated, as described in the Materials and Methods, and are plotted. Rats receiving a score between 1.0 and 0.25 were classed as STs, those with a score between 0.24 and -0.24 were classed as INs, and those with a score between -0.24 and -1.0 were classed as GTs.

sponses during the reinstatement test. Statistical significance was set at $p<0.05$.

\section{Results}

\section{Experiment 1}

Individual variation in PCA behavior

Figure 2 illustrates the degree of individual variation in PCA behavior in the PAIRED rats used in Experiment $1(n=28)$ by plotting the distribution of individual rat PCA index scores. Similar to our previous reports (Flagel et al., 2007; Saunders and Robinson, 2012), we found considerable variation in the form of the conditioned response (CR) that individual rats acquired. With training, some rats came to a preferentially direct approach behavior toward the CS (lever); that is, they acquired an ST CR. Rats with PCA index scores ranging from 0.25 to 1.0 were classed as STs. Other rats preferentially directed their CR toward the food cup during the CS period; that is, they acquired a GT CR. Those with PCA index scores ranging from -0.25 to -1.0 were classed as GTs. Finally, other rats vacillated between CS-directed and food cup-directed CRs. Those with PCA scores ranging from -0.24 to 0.24 were classed as INs. Note that the distribution of PCA scores for UNPAIRED rats was very similar to those of PAIRED rats, as was the UNPAIRED rat data for self-administration training and shock training, so, for the sake of simplicity, only data from the PAIRED groups are presented.

\section{Acquisition of cocaine self-administration in STs and GTs}

Consistent with previous reports (Saunders and Robinson, 2010, 2011; Yager and Robinson, 2013), there were no clear group differences in the acquisition of cocaine self-administration behavior (Fig. 3). STs and GTs did not differ in the overall number of active nose pokes (no effect of group: $F_{(1,18)}=0.746, p=0.399$; Fig. $3 A$ ), but they differed in responses made as a function of IC (group $\times$ infusion criterion interaction: $F_{(2,18)}=12.479, p<$ $0.001)$. There were no group differences in inactive nose pokes (no effect of group: $F_{(1,18)}=0.093, p=0.763$ ) made across the IC (no group $\times$ infusion criterion interaction: $F_{(2,18)}=1.096, p=$ 

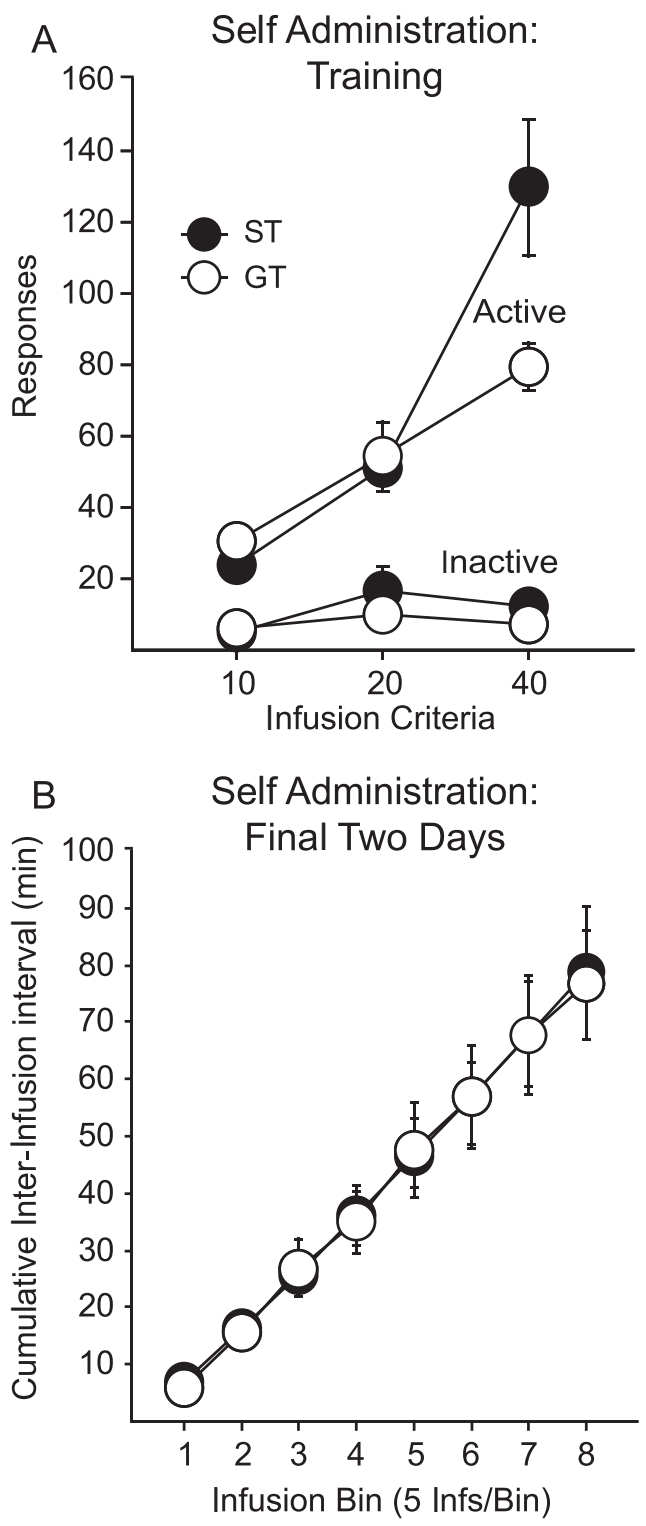

Figure 3. Acquisition of cocaine $(0.4 \mathrm{mg} / \mathrm{kg} /$ infusion) self-administration behavior in PAIRED STs $(n=10)$ and GTs $(n=10)$ in Experiment 1 . $\boldsymbol{A}$, The average number of active and inactive nose-poke responses made at ICs 10,20 , and $40 . \boldsymbol{B}$, The average cumulative interinfusion interval during the last two self-administration sessions at IC 40 . Symbols represent the means \pm SEM. Infs, Infusions.

$0.355)$. Given that active nose pokes were noticeably higher in STs than GTs at IC 40 (Fig. 3A), we further examined the pattern of self-administration behavior at the end of training by plotting within-session responding during the final two sessions at IC 40. This analysis showed that the pattern of cocaine selfadministration was nearly identical in STs and GTs, with both showing consistent and uniform rates of cocaine intake (Fig. 3B). Similar results were found for UNPAIRED rats (data not shown).

Cocaine self-administration in the face of adverse consequences Rats were next allowed to continue to self-administer cocaine, but to do so they had to walk across an electrified portion of the chamber floor. As footshock intensity increased, STs and GTs significantly decreased the number of cocaine infusions they took (effect of shock intensity: $F_{(5,25.891)}=52.613, p<0.001$; Fig. $4 A$ ). Figure $4 A$ shows there were no group differences in the number of infusions taken during the shock phase $\left(t_{(18)}=1.046, p=\right.$
0.309). There were also no group differences in the final shock intensity required to reduce responding to the criterion level of fewer than five infusions in a session $\left(t_{(18)}=1.73, p=0.463\right.$; Fig. $4 B)$. Thus, there was no indication that STs and GTs were differentially sensitive to the negative consequences of footshock.

Individual variation in the ability of a cocaine cue to evoke drugseeking behavior in the face of an aversive consequence

Total responses. We next tested the ability of the presentation of the cue (i.e., the light in the nose port), independent of any action, to spur drug-seeking behavior, as indicated by active nose pokes, even when making a nose-poke response would still require crossing the electrified floor but would not produce an injection of cocaine. Among PAIRED groups, both STs and GTs discriminated between active and inactive nose ports (effect of port: $\left.F_{(1,36)}=52.148, p<0.001\right)$. However, there were significant group differences in the degree of cue-evoked drug-seeking behavior (group $\times$ nose-poke interaction: $F_{(1,36)}=8.007, p=$ 0.008; Fig. $5 A$ ). A planned group comparison revealed that STs made significantly more active responses during the reinstatement test than GTs $\left(t_{(18)}=3.23, p=0.002\right)$. Additionally, the vigor of cue-evoked drug-seeking behavior, indicated by the total number of active responses, was significantly correlated with PCA index scores among the whole population of PAIRED rats tested. Indeed, variation in PCA index scores accounted for $25.3 \%$ of the variance in active responses during the reinstatement test $\left(R^{2}=0.253, p=0.003\right.$; Fig. $\left.5 B\right)$; that is, the more positive the PCA index score (greater sign-tracking behavior) the more drug-seeking behavior occurred during the reinstatement text.

Analysis of the UNPAIRED groups showed that the ability of the cue to reinstate drug-seeking behavior was due to its association with cocaine. Neither UNPAIRED STs nor UNPAIRED GTs reinstated, in that there was no difference between active and inactive responses (no effect of port: $F_{(1,26)}=2.608, p=0.118$ ), and UNPAIRED STs and UNPAIRED GTs did not differ from each other (no effect of group: $F_{(1,26)}=2.036, p=0.16$; no group $\times$ nose-poke interaction: $F_{(1,26)}=0.037, p=0.849$; Figure $5 C)$. Furthermore, in UNPAIRED rats there was no correlation between active responses made during the reinstatement test session and PCA index scores $\left(R^{2}=0.014, p=0.3030\right.$; Fig. $\left.5 D\right)$. Furthermore, direct comparison of active responses made by PAIRED and UNPAIRED rats indicated that PAIRED rats showed significantly greater cue-evoked reinstatement (group $\times$ nose-poke interaction: $\left.F_{(1,31)}=4.830, p=0.036\right)$.

As an additional control, on the reinstatement test day a group of PAIRED STs was placed back in the test chamber, but the cue was not presented. These no-cue rats made significantly fewer active responses than PAIRED STs exposed to the cue (group $\times$ nose-poke interaction: $F_{(1,30)}=5.257, p=0.029$; Fig. 6 ), and their responses were also not significantly different from PAIRED GTs exposed to the cue $\left(t_{(15)}=0.6311, p=0.5375\right)$.

Together, the comparison between the PAIRED and UNPAIRED groups indicates that the reinstatement of drug seeking in STs, even in the face of continued negative consequences, was due to the acquired motivational value of the cue, via its association with cocaine during training. In addition, the comparison of PAIRED STs exposed to the cue during the reinstatement test and PAIRED STs not exposed to the cue during the reinstatement test indicates that reinstatement was indeed cue evoked, and not merely the result of the forced period of abstinence (i.e., the incubation period). Nor was it due to re-exposure to the drug context after a reduction in shock intensity. 
CS active responses. We separately analyzed the number of active responses rats made specifically while the CS was illuminated (CS active responses). While this consists of a relatively short period of time relative to the entire reinstatement session, the results were similar to total active responses. PAIRED STs made significantly more active responses during noncontingent CS presentations, relative to GTs $\left(t_{(18)}=1.84, p=0.041\right.$; Fig. $\left.7 A\right)$, and this was significantly correlated with PCA index scores $\left(R^{2}=0.1980 ; p=0.0088\right.$; Fig. $7 B$ ). For UNPAIRED rats, STs and GTs did not differ in the number of CS active nose pokes $\left(t_{(13)}=1.771, p=\right.$ 0.0717; Fig. 7C), and there was no significant correlation between this behavior and PCA index scores $\left(R^{2}=0.0869, p=\right.$ 0.092; Fig. 7D).

Distribution of responses. Finally, we examined the distribution of active responses made by STs during the period that the cocaine cue was present (while the light in the nose port was on; the cue period) relative to responses during the remainder of the reinstatement test session (the no-cue period). During the $30 \mathrm{~min}$ test session, the cue was presented 10 times (for $20 \mathrm{~s}$ every $3 \mathrm{~min}$ ). Thus, as shown in Figure 8, the cue was present for $11 \%$ of the total reinstatement test session. Interestingly, in STs the percentage of total active responses made during the cue period was $15 \%$; that is, $85 \%$ of the active responses occurred when the cue was not present (Fig. 8). This indicates that active responses were emitted essentially in proportion to the time available. This was confirmed by analysis of the rate of responding during the cue versus no-cue periods. STs made 0.022 (SEM $=0.007)$ responses per second during the cue period, which did not differ from the rate of responding during the no-cue period (mean $=0.017$ responses $/ \mathrm{s} ; \mathrm{SEM}=0.003$ responses/s; paired $t$ test, $t_{(9)}=0.556, p=$ 0.2960).

It was possible that the increase in active responses seen in PAIRED versus UNPAIRED STs during the reinstatement test was a function of the light cue eliciting an approach response, and, given that the light cue was located within the nose port, this could increase the probability of a rat making a nose poke (Tomie, 1996). However, the fact that ST responding was similarly higher during both cue and no-cue periods suggests that this was not the case; that is, in this situation cue-evoked cocaine seeking in STs was not simply a function of the cue eliciting approach behavior (i.e., an ST CR). Consistent with
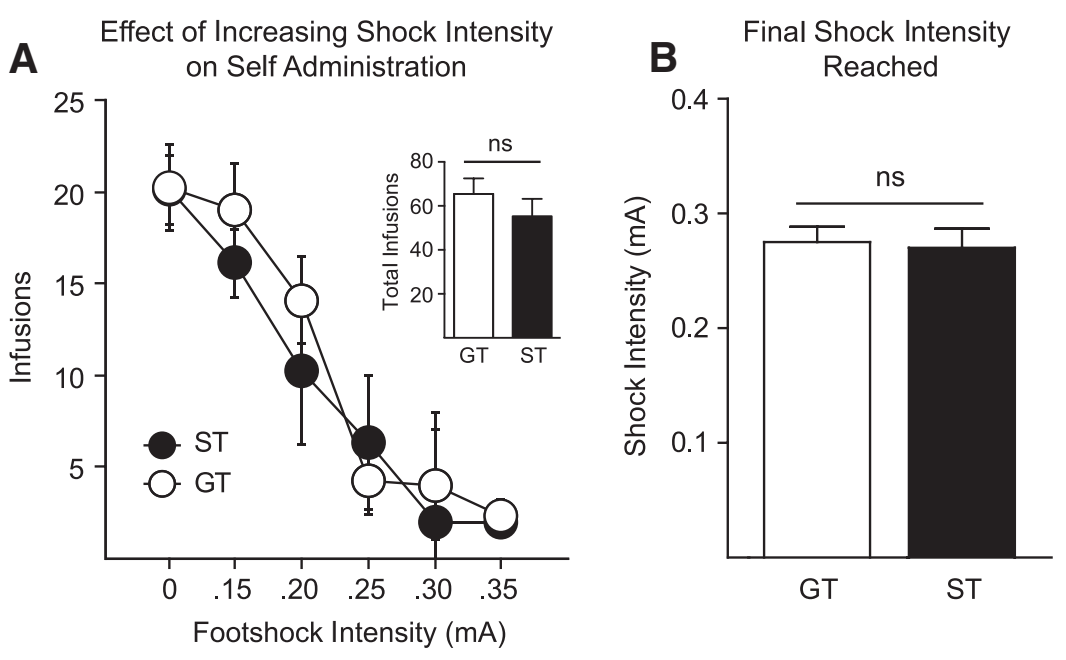

Figure 4. Self-administration in the face of an adverse consequence (Experiment 1). $\boldsymbol{A}$, Average number of cocaine infusions taken at escalating footshock intensities for PAIRED STs $(n=10)$ and GTs $(n=10)$, and total infusions taken (inset) in Experiment 1. $B$, Average final footshock intensity reached per group. Symbols represent the means \pm SEM. ns, Not significant (at $p<0.05)$; $\mathrm{mA}$, milliamps.

\section{Individual Variation in Cocaine Cue-Evoked Reinstatement}
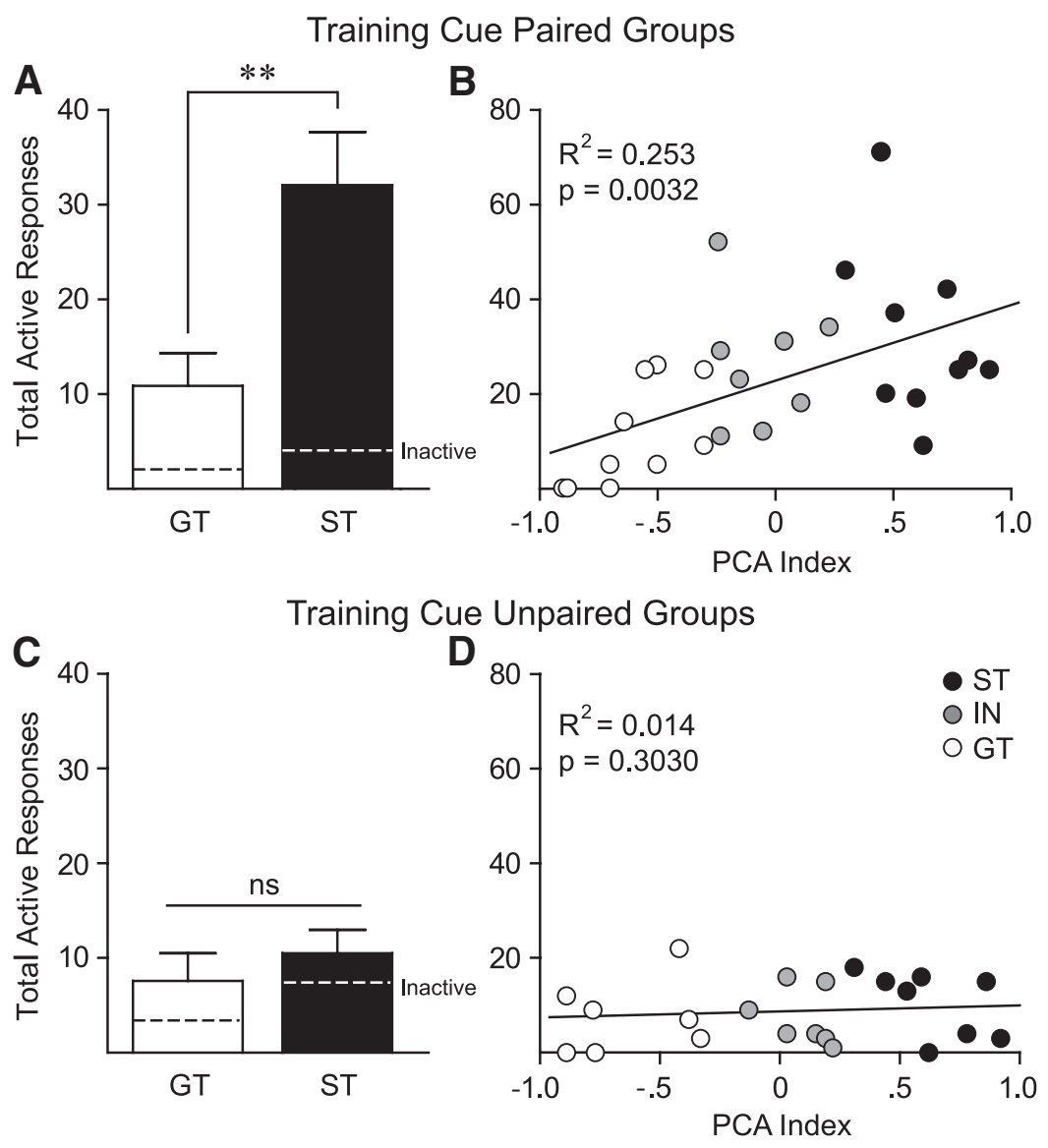

Figure 5. Individual variation in cue-evoked reinstatement. $\boldsymbol{A}$, Average total active nose pokes made during the 30 min reinstatement test for PAIRED STs $(n=10)$ and GTs $(n=10)$ in Experiment 1. Dashed lines within the bars represent inactive nose pokes. $\boldsymbol{B}$, Total number of active responses made during the reinstatement test for each PAIRED rat in Experiment 1, as a function of PCA index score. Note that INs $(n=8)$ were included here to illustrate the relationship across the entire distribution of PCA scores. C, Average total active nose pokes made during the 30 min reinstatement test for UNPAIRED STs $(n=8)$ and GTs $(n=7)$ in Experiment 1. Dashed lines represent inactive nose pokes. $D$, Total number of active responses made during the reinstatement test for each UNPAIRED rat in Experiment 1, as a function of PCA index score. UNPAIRED INs $(n=7)$ are shown to illustrate the relationship across the entire PCA score range. Symbols represent the means $\pm S E M$. ${ }^{* *} p<0.01$. ns, Not significant (at $\left.p>0.05\right)$. 


\section{ST Reinstatement in the Presence vs. Absence of a Drug Cue}

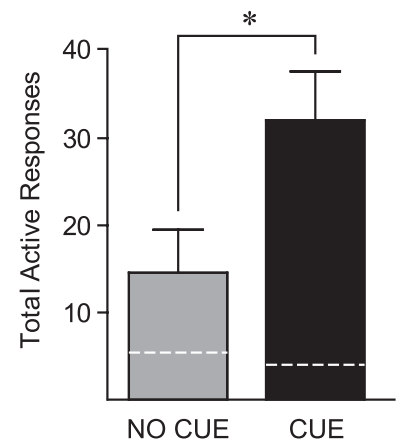

Figure 6. Cue-evoked versus uncued reinstatement in PAIRED STs. Average total active nose pokes made during the $30 \mathrm{~min}$ reinstatement test for PAIRED STs that received noncontingent cue presentations during reinstatement $(n=10)$ and PAIRED STs that did not receive cue presentations during reinstatement $(n=7)$. Dashed lines represent inactive nose pokes. Symbols represent the means \pm SEM. ${ }^{*} p<0.05$.

\section{Individual Variation in Cocaine Cue-Evoked Reinstatement}

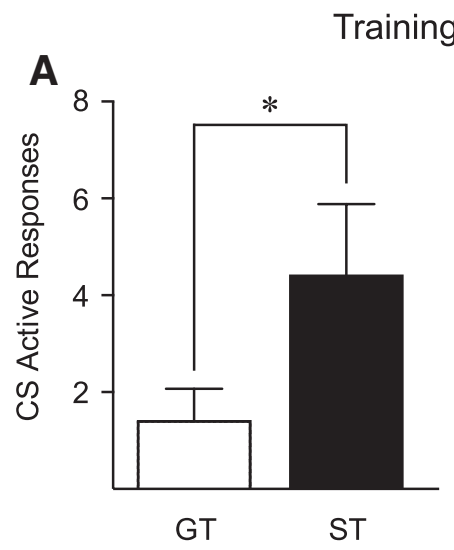

B
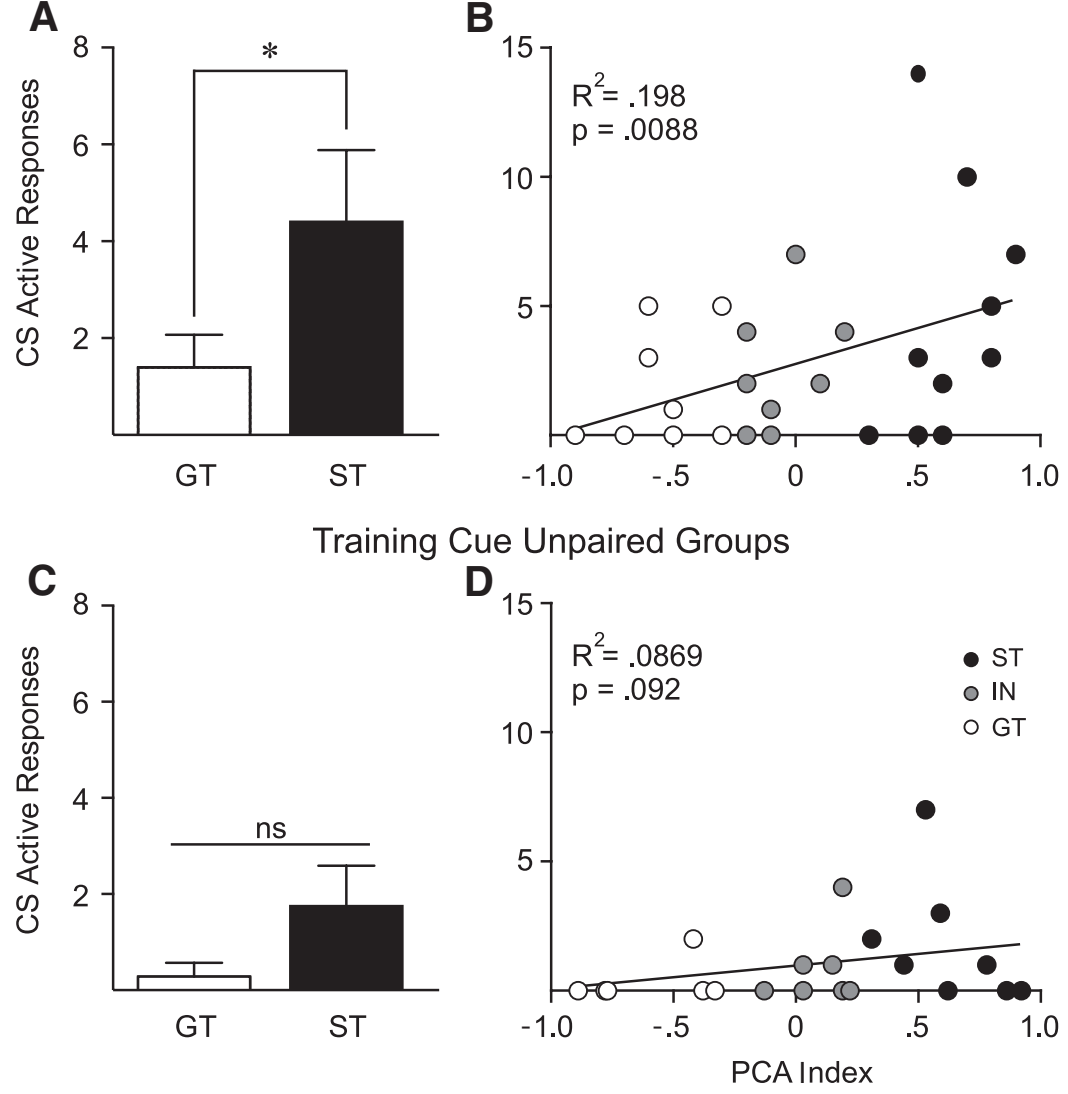

Figure 7. Individual variation in cue-evoked reinstatement-noncontingent cocaine cue responses. $\boldsymbol{A}$, Average active nose pokes made during noncontingent cocaine cue presentations (CS active responses) in the 30 min reinstatement test for PAIRED STS $(n=10)$ and GTs $(n=10)$ in Experiment 1. $\boldsymbol{B}$, Active responses made during noncontingent cue presentations for each PAIRED rat in Experiment 1 , as a function of PCA index score. $C$, Average active nose pokes made during noncontingent cue presentations for UNPAIRED STs $(n=8)$ and GTs $(n=7)$ in Experiment 1. D, Active responses made during noncontingent cue presentations for each UNPAIRED rat in Experiment 1, as a function of PCA index score. Symbols represent the means \pm SEM. ${ }^{*} p<0.05$. ns, Not significant (at $p>0.05$ ).

this interpretation, sign tracking to a light paired with cocaine is tightly coupled to the cue period (Yager and Robinson, 2013), which contrasts with the results here. Therefore, although the ability of the light cue to elicit approach behavior may have con- tributed to active responses during the cue period, we suggest that active responses during the no-cue period, which account for by far the majority of active responses, reflects the influence of a cue-evoked conditioned motivational state (craving) that persists beyond the relatively brief period of cue presentation. , throughout the reinstatement test session STs may ever-present footshock. At any given moment in STs the desire for drug a often than in GTs. Of course, it is difficult to tell whether the cue-evoked motivational state is weaker in GTs than in STs, or whether GTs desire to avoid the shock is stronger. Given that there was no difference between STs and GTs in the shock intensity necessary to curtail responding for cocaine (Fig. 4), we suggest it is most likely the former.

\section{Experiment 2}

Pavlovian training, acquisition of cocaine self-administration, and selfadministration during the shock phase were very similar to Experiment 1, so for the sake of simplicity those data are not shown.

Dopamine receptor blockade in the nucleus accumbens core preferentially suppresses cue-evoked drug seeking in STs

We first compared STs and GTs who received vehicle before the reinstatement test and found that STs reinstated to a significantly greater degree than GTs (group $\times$ nose-poke interaction: $F_{(1,24)}=6.893, p=0.015$; Fig. $\left.9 A\right)$. This provides an independent replication of this finding from Experiment 1. Flupenthixol suppressed cue-evoked drug seeking relative to vehicle in both STs and GTs (effect of treatment: $F_{(1,25)}=28.158, p<$ $0.001)$. However, it did so to a significantly greater degree in STs than in GTs, as indicated by a significant interaction effect (group $\times$ treatment interaction: $\left.F_{(1,25)}=6.753, p=0.015\right)$. Note that the interaction term controls for group differences in baseline levels of responding. Furthermore, in STs flupenthixol suppressed active responses to a greater extent than inactive responses, indicating that the effect was not due to nonspecific motor impairments (treatment $\times$ nosepoke interaction for STs: $F_{(1,28)}=39.686$, $p<0.001)$. Finally, we found that in STs, but not in GTs, flupenthixol significantly reduced the number of active responses made during the $20 \mathrm{~s}$ periods that the cocaine CS was present, relative to vehicle (STs: $t_{(14)}=2.166, p=0.024$; GTs: $t_{(11)}=$ 1.322, $p=0.106$; Fig. 9B). We should note, however, that GTs made very few responses during the CS period even after vehicle administration, so there is likely a floor effect to their suppression. 
The locations of injector tips in the nucleus accumbens core for flupenthixol and vehicle groups are illustrated in Figure $9 C$.

Amphetamine in the accumbens core preferentially enhances cueevoked drug seeking in STs

Amphetamine increased total active responses relative to vehicle levels in both STs and GTs (effect of treatment: $F_{(1,24)}=15.134$, $p=0.001$; Fig. $10 A$ ), and there was a trend toward preferential enhancement of total active responding in STs, relative to GTs, although this effect did not reach statistical significance (no group $\times$ treatment interaction: $\left.F_{(1,24)}=4.083, p=0.055\right)$. We analyzed the effect of amphetamine on active versus inactive responding, within each group. Amphetamine preferentially enhanced responding at the active nose poke in STs (treatment $X$ nose-poke interaction for STs: $\left.F_{(1,26)}=10.512, p=0.003\right)$, but not GTs (no treatment $\times$ nose-poke interaction for GTs: $F_{(1,22)}=$ 4.165, $p=0.053$ ), suggesting that the increased reinstatement effect in STs was not due to a nonspecific enhancement of behavior. Importantly, we separately analyzed the effects of amphetamine specifically on CS active responses. Relative to vehicle, amphetamine caused an increase in the number of CS active responses (effect of treatment: $F_{(1,24)}=10.397, p<0.004$; Fig. $10 B)$, and this potentiation effect was greater in STs than in GTs (group $\times$ treatment interaction: $F_{(1,24)}=5.028, p=$ 0.034).

Given that amphetamine administration increased the number of active nose pokes that STs made during cue presentations, it is possible that this manipulation preferentially increased the attractiveness of the cocaine cue in STs, rather than increasing the ability of the cue to evoke a conditioned motivational state that instigated drug seeking. To examine this, as in Experiment 1 (see above), we analyzed the rate of responding during the cue versus no-cue periods for STs that received amphetamine microinjections in the core. Response rates were elevated, relative to the vehicle control group, during both periods, but there were no differences between the cue and no-cue periods (paired $t$ test, $t_{(6)}=$ 1.398, $p=0.1058$; cue period: mean $=$ 0.0829 responses/s; $\mathrm{SEM}=0.0250$ responses/s; no-cue period: mean $=0.0525$ responses/s; SEM = 0.0109 responses/s). Furthermore, following amphetamine administration STs still made the vast majority of their active responses during the no-cue period (cue period: $17 \%$ of total responses; no-cue period: $83 \%$ of total responses). This suggests that amphetamine increased reinstatement in STs primarily by enhancing the ability of the cue to evoke a motivational state for cocaine that was not tightly locked to the cue period, rather than by simply increasing approach to the cue itself.

The locations of injector tips in the nucleus accumbens core for amphetamine and vehicle groups are illustrated in Figure $10 C$.

\section{Distribution of Responses Made During Reinstatement by Sign-trackers}

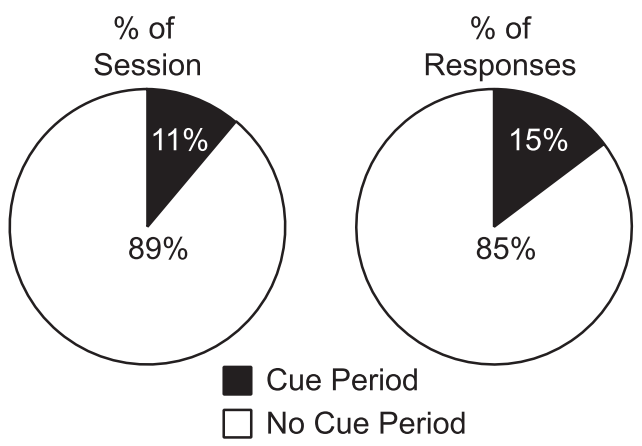

Figure 8. Distribution of active responses for PAIRED STs. Left pie chart, Breakdown of the percentage of the reinstatement session during which the cue was present (cued) versus the no-cue period. Right pie chart, The percentage of total active responses made by PAIRED STs in cue versus no-cue periods during the reinstatement test session.

\section{Effect of Blocking Accumbens Core Dopamine Signaling on Cue-Evoked Reinstatement}
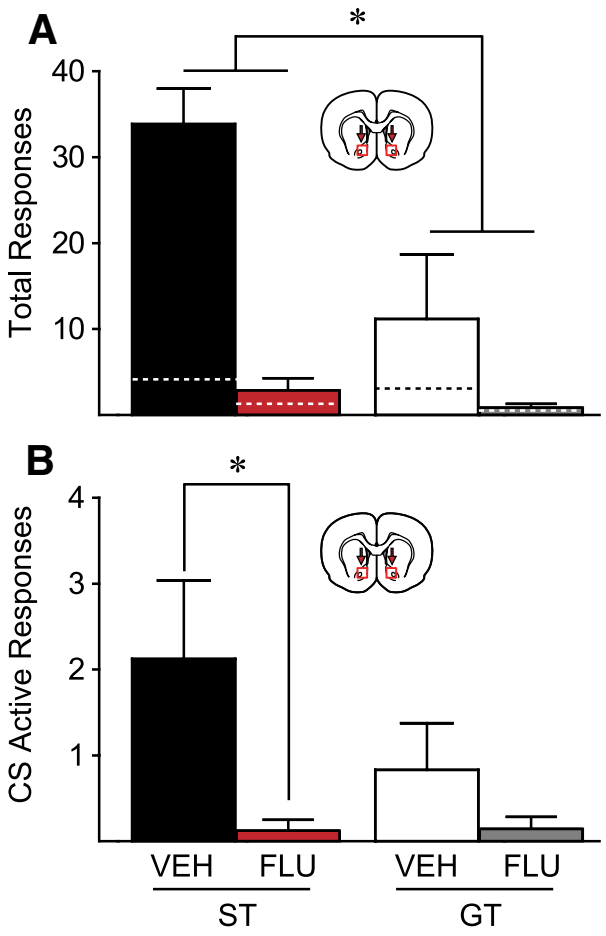

C

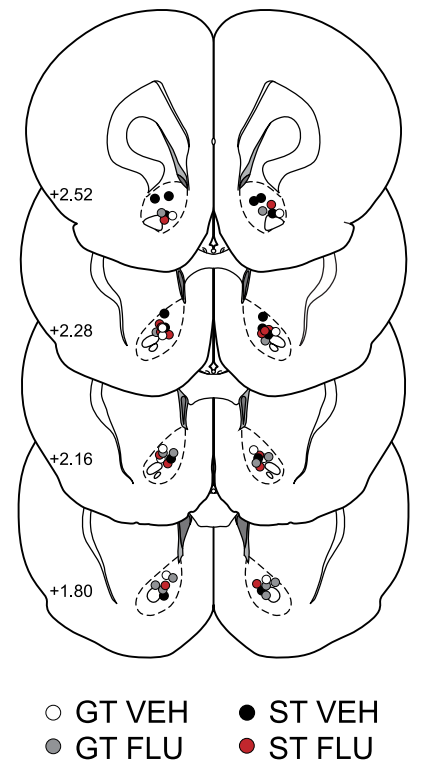

Figure 9. Effect of accumbens core dopamine receptor blockade on individual variation in cue-evoked reinstatement. $\boldsymbol{A}$, Average total active responses made for rats that received either vehicle or flupenthixol ( $20 \mu \mathrm{g})$ in the nucleus accumbens core before the reinstatement test. $\boldsymbol{B}$, Average number of active responses made during CS periods in the reinstatement test for vehicle- and flupenthixol-treated rats. C, Location of microinjection tips within the nucleus accumbens core relative to bregma for flupenthixol and vehicle rats. Symbols represent the means \pm SEM. ${ }^{*} p<0.05$.

\section{Discussion}

Drug-associated stimuli promote relapse via the following three interacting mechanisms: by eliciting approach; by acting as conditioned reinforcers; and/or by evoking conditioned motivational states that spur seeking (Milton and Everitt, 2010). The conditioned reinforcing effects of drug cues have been well characterized in preclinical studies (Shaham et al., 2003; Marchant et al., 2013). However, the ability of drug cues to arouse conditioned motivation for drugs (craving), which may be especially 


\section{Effect of Intra-Accumbens Core Amphetamine on Cue-Evoked Reinstatement}
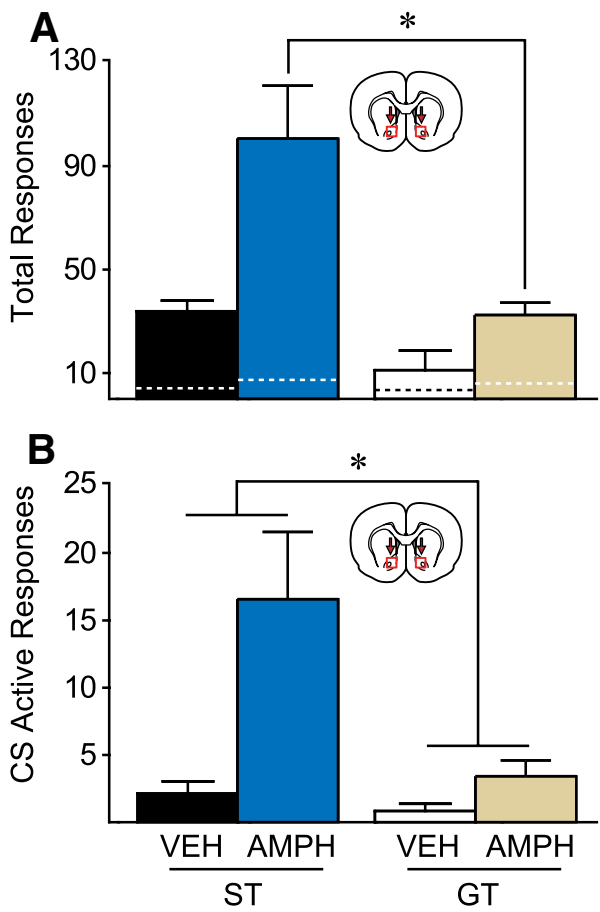

Figure 10. Effect of intra-accumbens core amphetamine on individual variation in cue-evoked reinstatement. $\boldsymbol{A}$, Average total active responses made during the reinstatement test for rats treated with vehicle or amphetamine $(10 \mu \mathrm{g})$ in the nucleus accumbens core. $\boldsymbol{B}$, Average $C S$ active responses for vehicle- and amphetamine-treated rats. $\boldsymbol{C}$, Location of microinjection tips within the nucleus accumbens core relative to bregma for amphetamine and vehicle rats (note: vehicle placements shown here are the same as in Fig. 9C). Symbols represent the means \pm SEM. ${ }^{*} p<0.05$.

important for ongoing drug use and relapse (Preston et al., 2009), has received little attention. To better understand the role of conditioned motivation in evoking drug-seeking behavior, we adopted a conflict-based model of relapse developed by Cooper et al. (2007). We found the following: (1) noncontingent presentation of a cocaine cue reinstated drug-seeking behavior that had been nearly abolished by imposition of an adverse consequence (footshock), and despite the continued presence of shock; (2) there was considerable individual variation in the ability of the cue to instigate responding (Cooper et al., 2007; Barnea-Ygael et al., 2012; Peck et al., 2013); (3) most importantly, 25\% of this variation was predicted by the propensity of individuals to attribute incentive salience to a food cue (i.e., the cocaine cue was more effective in STs than GTs); and (4) the effectiveness of the cue in motivating drug seeking was attenuated by an injection of a dopamine antagonist into the core of the accumbens and potentiated by an injection of amphetamine, preferentially in STs.

\section{Preclinical models of relapse}

There are some limitations with the construct validity of the traditional extinction-reinstatement procedure as a model of relapse (Katz and Higgins, 2003; Epstein et al., 2006). One, in addicts, cues usually provoke (motivate) actions to procure drugs, rather than reinforce actions already taken. Two, addicts rarely undergo extinction training, but typically forgo drug use due to rising negative costs (e.g., poor health, financial limitations, or incarceration; Epstein and Preston, 2003). However, following extinction of self-administration behavior, the noncontingent presentation of drug cues is not very effective in producing reinstatement (de Wit and Stewart, 1981; Grimm et al.,
2000; Kruzich et al., 2001) or they produce only very low levels of responding (Deroche-Gamonet et al., 2002; but see Barker et al., 2012). An additional complication is that extinction training induces brain plasticity mechanisms that act to inhibit future drug seeking (Knackstedt et al., 2010), and, compared with abstinence, after extinction training different neural systems become involved in reinstatement (Fuchs et al., 2006).

The conflict-based relapse model used here better isolates the ability of a drug cue to evoke drug seeking, presumably by generating a conditioned motivational state. Evidence that the reinstatement in STs observed here was in fact due to cue-evoked conditioned motivation, and not simply attraction to the cue or a stimulus-response habit, is supported by our analysis showing that most active responses were not tightly coupled to the period the cue was physically present. Psychologically, cueevoked conditioned motivation, as described here, probably relies on very similar mechanisms to that responsible for traditional PIT effects. Indeed, Barker et al. (2012) recently reported that an alcoholassociated cue produced the most reinstatement in mice that show the greatest PIT in response to a food-associated cue. We have previously reported that STs are also more prone to reinstatement using traditional extinction-reinstatement procedures based on conditioned reinforcement (Saunders and Robinson, 2010), and STs are more attracted to a cocaine cue than GTs (Yager and Robinson, 2013). It would seem, therefore, at least in the case of discrete cues (Robinson et al., 2013), that STs are more susceptible to all "three routes to relapse," as described by Milton and Everitt (2010; for review, see Saunders and Robinson, 2013).

\section{Dopamine and cue-evoked drug seeking}

Dopamine signaling is critical in transforming motivationally "cold" CSs into attractive and invigorating incentive stimuli (Robinson and Berridge, 1993; Berridge, 2007, 2012). For example, dopamine-specific lesions or receptor blockade attenuates sign-tracking CRs and conditioned reinforcement for foodassociated stimuli (Taylor and Robbins, 1986; Di Ciano et al., 2001; Hall et al., 2001; Flagel et al., 2011b; Saunders and Robinson, 2012; Clark et al., 2013). Conversely, potentiation of dopamine release increases sign-tracking behavior (Hitchcott et al., 1997; Phillips et al., 2003; but see Simon et al., 2009; Holden and Peoples, 2010) and also enhances the conditioned reinforcing effects of cues (Hill, 1970; Robbins, 1976; Taylor and Robbins, 1984; Collins et al., 2012). Dopamine signaling is also necessary for pavlovian food cues to produce conditioned motivation, as measured with PIT procedures (Dickinson et al., 2000; Wyvell and Berridge, 2000, 2001; Lex and Hauber, 2008; Aragona et al., 2009; Saddoris et al., 2011; Wassum et al., 2011, 2013; Ostlund and Maidment, 2012). However, it has not been established whether dopamine plays a similar role in cocaine cue-conditioned motivation (LeBlanc et al., 2012; p. 687). Assuming that the cue-evoked motivation for cocaine 
described here relies on similar mechanisms as PIT, our results suggest that it likely does. Endogenous dopamine signalingand potentially other monoamines affected by amphetamine, such as norepinephrine (Seiden et al., 1993; Schroeder et al., 2013) —within the accumbens core appears to be both necessary for cocaine cue-evoked conditioned motivation and sufficient to enhance such conditioned motivation. In future experiments, it will be critical to establish the role of dopamine in regions outside of the accumbens core in these processes.

\section{Clinical relevance}

Our preclinical results are consistent with the growing human literature demonstrating that drug craving is a major factor contributing to drug use and relapse in addicts. Conditioned motivational states can be elicited by drug-associated stimuli that instigate drug-seeking behavior implicitly, or that rise to conscious awareness, where they can be measured as subjective craving (Fischman, 1989; Jaffe et al., 1989; Fischman and Foltin, 1992). This has been nicely demonstrated by recent "real-world" studies using ecological momentary assessment methods, wherein addicts report their craving levels in real time, often as they go about their daily lives (Stone and Shiffman, 1994; Shiffman et al., 2002; Preston et al., 2009). Addicts report surges in craving, frequently triggered by the presence of drug-associated stimuli, directly preceding drug use, which is a finding that raises the possibility that craving may be causally involved in ongoing drug use in humans. Our results suggest that it is possible to model this cue-evoked drug craving in rodents, and that individual differences in the degree to which discrete cues acquire conditioned motivational properties is one important factor associated with vulnerability to cue-evoked relapse.

Drug cues are thought to promote craving and drug-seeking behavior in addicts by engaging mesocorticolimbic circuitry (Ehrman et al., 1992; Childress et al., 1999, 2008; Sinha, 2013), including dopamine systems. In cocaine addicts, for example, viewing images of drug-associated cues causes dopamine surges within the striatum, the magnitude of which is positively correlated with self-reported subjective craving (Volkow et al., 2006; Wong et al., 2006; Boileau et al., 2007). Thus, individual differences in drug cue responsivity are directly related to the ability of the cue to engage dopamine systems. This is supported by studies showing that, in individuals with genetic polymorphisms resulting in elevated dopamine transmission, drug cues produce greater activation in a variety of brain regions and/or higher levels of craving (Noble, 2000; Hutchison et al., 2002; McClernon et al., 2007; Franklin et al., 2009). Our preclinical results are consistent with these findings and suggest that endogenous dopamine signaling, at least within the nucleus accumbens core, is necessary for drug cue-evoked conditioned craving powerful enough to spur drug seeking. Importantly, we also found that dopamine manipulations preferentially affected a subset of rats (STs), consistent with previous studies demonstrating that reward cues engage mesocorticolimbic circuitry more in STs (Flagel et al., 2011a), and that STs have "hyperactive" dopamine systems (Flagel et al., 2007, 2010) compared with GTs. Together, these converging human and rodent studies suggest that some individuals exhibit enhanced brain and behavioral activation in response to drug cues, which may make them more prone to continued drug seeking and relapse.

We should also point out that dopamine has other, potentially broader, roles in the processing of drug cues, such as regulating the degree to which they bias the attention of addicts (Franken et al., 2004; Munafò et al., 2007; Hitsman et al., 2008; Ersche et al., 2010), although attentional bias and conditioned motivation are likely linked (Saunders and Robinson, 2013). Alterations in frontal cortical circuitry, in addition to those in dopamine systems, may mediate such attentional processes (Hester and Garavan, 2004; Ersche et al., 2010; Sinha, 2013). Thus, exaggerated attention to, and motivation evoked by, drug cues is likely due to adaptations in both "top-down" cortical circuitry and "bottomup" mesolimbic dopamine systems. Interestingly, we recently reported that STs have relatively poor attentional control, relative to GTs, and that this was related to attenuated acetylcholine neurotransmission in the prefrontal cortex (Paolone et al., 2013).

In conclusion, we suggest that drug cues may be particularly powerful instigators of relapse in a subset of susceptible individuals, in part by evoking dopamine-mediated conditioned craving for drugs.

\section{References}

Aragona BJ, Day JJ, Roitman MF, Cleaveland NA, Wightman RM, Carelli RM (2009) Regional specificity in the real-time development of phasic dopamine transmission patterns during acquisition of a cue-cocaine association in rats. Eur J Neurosci 30:1889-1899. CrossRef Medline

Barker JM, Torregrossa MM, Taylor JR (2012) Low prefrontal PSA-NCAM confers risk for alcoholism-related behavior. Nat Neurosci 15:1356-1358. CrossRef Medline

Barnea-Ygael N, Yadid G, Yaka R, Ben-Shahar O, Zangen A (2012) Cueinduced reinstatement of cocaine seeking in the rat "conflict model": effect of prolonged home-cage confinement. Psychopharmacology 219: 875-883. CrossRef Medline

Berridge KC (2007) The debate over dopamine's role in reward: the case for incentive salience. Psychopharmacology (Berl) 191:391-431. CrossRef Medline

Berridge KC (2012) From prediction error to incentive salience: mesolimbic computation of reward motivation. Eur J Neurosci 35:1124-1143. CrossRef Medline

Bertz J, Woods J (2013) Acquisition of responding with a remifentanilassociated conditioned reinforcer in the rat. Psychopharmacology. Advance online publication. doi:10.1007/s00213-013-3102-0. CrossRef Medline

Bindra D (1978) How adaptive behavior is produced: a perceptualmotivation alternative to response reinforcement. Behav Brain Sci 1:41-91. CrossRef

Boileau I, Dagher A, Leyton M, Welfeld K, Booij L, Diksic M, Benkelfat C (2007) Conditioned dopamine release in humans: a positron emission tomography $[11 \mathrm{C}]$ raclopride study with amphetamine. J Neurosci 27 : 3998-4003. CrossRef Medline

Bossert J, Marchant N, Calu D, Shaham Y (2013) The reinstatement model of drug relapse: recent neurobiological findings, emerging research topics, and translational research. Psychopharmacology. Advance online publication. doi:10.1007/s00213-013-3120-y. CrossRef Medline

Cardinal RN, Parkinson JA, Hall J, Everitt BJ (2002) Emotion and motivation: the role of the amygdala, ventral striatum, and prefrontal cortex. Neurosci Biobehav Rev 26:321-352. CrossRef Medline

Carter BL, Tiffany ST (1999) Meta-analysis of cue-reactivity in addiction research. Addiction 94:327-340. CrossRef Medline

Childress AR, Mozley PD, McElgin W, Fitzgerald J, Reivich M, O’Brien CP (1999) Limbic activation during cue-induced cocaine craving. Am J Psychiatry 156:11-18. Medline

Childress AR, Ehrman RN, Wang Z, Li Y, Sciortino N, Hakun J, Jens W, Suh J, Listerud J, Marquez K, Franklin T, Langleben D, Detre J, O’Brien CP (2008) Prelude to passion: limbic activation by "unseen" drug and sexual cues. PLoS One 3:e1506. CrossRef Medline

Clark JJ, Collins AL, Sanford CA, Phillips PE (2013) Dopamine encoding of pavlovian incentive stimuli diminishes with extended training. J Neurosci 33:3526-3532. CrossRef Medline

Collins GT, Cunningham AR, Chen J, Wang S, Newman AH, Woods JH (2012) Effects of pramipexole on the reinforcing effectiveness of stimuli that were previously paired with cocaine reinforcement in rats. Psychopharmacology (Berl) 219:123-135. CrossRef Medline

Cooper A, Barnea-Ygael N, Levy D, Shaham Y, Zangen A (2007) A conflict rat model of cue-induced relapse to cocaine seeking. Psychopharmacology 194:117-125. CrossRef Medline 
Corbit LH, Janak PH (2007) Ethanol-associated cues produce general pavlovian-instrumental transfer. Alcohol Clin Exp Res 31:766-774. CrossRef Medline

Crombag HS, Badiani A, Maren S, Robinson TE (2000) The role of contextual versus discrete drug-associated cues in promoting the induction of psychomotor sensitization to intravenous amphetamine. Behav Brain Res 116:1-22. CrossRef Medline

Deroche-Gamonet V, Piat F, Le Moal M, Piazza PV (2002) Influence of cue-conditioning on acquisition, maintenance and relapse of cocaine intravenous self-administration. Eur J Neurosci 15:1363-1370. CrossRef Medline

de Wit H, Stewart J (1981) Reinstatement of cocaine-reinforced responding in the rat. Psychopharmacology 75:134-143. CrossRef Medline

Di Ciano P, Cardinal RN, Cowell RA, Little SJ, Everitt BJ (2001) Differential involvement of NMDA, AMPA/kainate, and dopamine receptors in the nucleus accumbens core in the acquisition and performance of pavlovian approach behavior. J Neurosci 21:9471-9477. Medline

Dickinson A, Smith J, Mirenowicz J (2000) Dissociation of pavlovian and instrumental incentive learning under dopamine antagonists. Behav Neurosci 114:468-483. CrossRef Medline

Ehrman RN, Robbins SJ, Childress AR, O’Brien CP (1992) Conditionedresponses to cocaine-related stimuli in cocaine abuse patients. Psychopharmacology 107:523-529. CrossRef Medline

Epstein DH, Preston KL (2003) The reinstatement model and relapse prevention: a clinical perspective. Psychopharmacology 168:31-41. CrossRef Medline

Epstein DH, Preston KL, Stewart J, Shaham Y (2006) Toward a model of drug relapse: an assessment of the validity of the reinstatement procedure. Psychopharmacology 189:1-16. CrossRef Medline

Ersche KD, Bullmore ET, Craig KJ, Shabbir SS, Abbott S, Müller U, Ooi C, Suckling J, Barnes A, Sahakian BJ, Merlo-Pich EV, Robbins TW (2010) Influence of compulsivity of drug abuse on dopaminergic modulation of attentional bias in stimulant dependence. Arch Gen Psychiatry 67:632-644. CrossRef Medline

Estes WK (1943) Discriminative conditioning. I. A discriminative property of conditioned anticipation. J Exp Psychol 32:150-155. CrossRef

Estes WK (1948) Discriminative conditioning. II. Effects of a Pavlovian conditioned stimulus upon a subsequently established operant response. J Exp Psychol 38:173-177. CrossRef Medline

Fischman MW (1989) Relationship between self-reported drug effects and their reinforcing effects: studies with stimulant drugs. NIDA Res Monogr 92:211-230. Medline

Fischman MW, Foltin RW (1992) Self-administration of cocaine by humans: a laboratory perspective. Ciba Found Symp 166:165-173. Medline

Flagel SB, Watson SJ, Robinson TE, Akil H (2007) Individual differences in the propensity to approach signals vs goals promote different adaptations in the dopamine system of rats. Psychopharmacology (Berl) 191:599607. CrossRef Medline

Flagel SB, Akil H, Robinson TE (2009) Individual differences in the attribution of incentive salience to reward-related cues: implications for addiction. Neuropharmacology 56:139-148. CrossRef Medline

Flagel SB, Robinson TE, Clark JJ, Clinton SM, Watson SJ, Seeman P, Phillips PE, Akil H (2010) An animal model of genetic vulnerability to behavioral disinhibition and responsiveness to reward-related cues: implications for addiction. Neuropsychopharmacology 35:388-400. CrossRef Medline

Flagel SB, Cameron CM, Pickup KN, Watson SJ, Akil H, Robinson TE (2011a) A food predictive cue must be attributed with incentive salience for it to induce c-fos mRNA expression in cortico-striatal-thalamic brain regions. Neuroscience 196:80-96. CrossRef Medline

Flagel SB, Clark JJ, Robinson TE, Mayo L, Czuj A, Willuhn I, Akers CA, Clinton SM, Phillips PE, Akil H (2011b) A selective role for dopamine in stimulus-reward learning. Nature 469:53-57. CrossRef Medline

Franken IH, Hendriks VM, Stam CJ, Van den Brink W (2004) A role for dopamine in the processing of drug cues in heroin dependent patients. Eur Neuropsychopharmacol 14:503-508. CrossRef Medline

Franklin TR, Lohoff FW, Wang Z, Sciortino N, Harper D, Li Y, Jens W, Cruz J, Kampman K, Ehrman R, Berrettini W, Detre JA, O’Brien CP, Childress AR (2009) DAT genotype modulates brain and behavioral responses elicited by cigarette cues. Neuropsychopharmacology 34:717-728. CrossRef Medline

Fuchs RA, Branham RK, See RE (2006) Different neural substrates mediate cocaine seeking after abstinence versus extinction training: a critical role for the dorsolateral caudate-putamen. J Neurosci 26:3584-3588. CrossRef Medline

Grimm JW, Kruzich PJ, See RE (2000) Contingent access to stimuli associated with cocaine self-administration is required for reinstatement of drug-seeking behavior. Psychobiology 28:383-386.

Grimm JW, Hope BT, Wise RA, Shaham Y (2001) Neuroadaptation-incubation of cocaine craving after withdrawal. Nature 412:141-142. CrossRef Medline

Hall J, Parkinson JA, Connor TM, Dickinson A, Everitt BJ (2001) Involvement of the central nucleus of the amygdala and nucleus accumbens core in mediating Pavlovian influences on instrumental behaviour. Eur J Neurosci 13:1984-1992. CrossRef Medline

Hester R, Garavan H (2004) Executive dysfunction in cocaine addiction: evidence for discordant frontal, cingulate, and cerebellar activity. J Neurosci 24:11017-11022. CrossRef Medline

Hill RT (1970) Facilitation of conditioned reinforcement as a mechanism of psychomotor stimulation. In: Amphetamine and related compounds (Costa E, Garattini S, eds), pp 781-795. New York: Raven.

Hitchcott PK, Harmer CJ, Phillips GD (1997) Enhanced acquisition of discriminative approach following intra-amygdala d-amphetamine. Psychopharmacology 132:237-246. CrossRef Medline

Hitsman B, MacKillop J, Lingford-Hughes A, Williams TM, Ahmad F, Adams S, Nutt DJ, Munafo MR (2008) Effects of acute tyrosine/phenylalanine depletion on the selective processing of smoking-related cues and the relative value of cigarettes in smokers. Psychopharmacology (Berl) 196: 611-621. CrossRef Medline

Holden JM, Peoples LL (2010) Effects of acute amphetamine exposure on two kinds of Pavlovian approach behavior. Behav Brain Res 208:270-273. CrossRef Medline

Hutchison KE, LaChance H, Niaura R, Bryan A, Smolen A (2002) The DRD4 VNTR polymorphism influences reactivity to smoking cues. J Abnorm Psychol 111:134-143. CrossRef Medline

Ikemoto S, Panksepp J (1999) The role of nucleus accumbens dopamine in motivated behavior: a unifying interpretation with special reference to reward-seeking. Brain Res Brain Res Rev 31:6-41. CrossRef Medline

Ito R, Hayen A (2011) Opposing roles of nucleus accumbens core and shell dopamine in the modulation of limbic information processing. J Neurosci 31:6001-6007. CrossRef Medline

Jaffe JH, Cascella NG, Kumor KM, Sherer MA (1989) Cocaine-induced cocaine craving. Psychopharmacology 97:59-64. CrossRef Medline

Katz JL, Higgins ST (2003) The validity of the reinstatement model of craving and relapse to drug use. Psychopharmacology 168:21-30. CrossRef Medline

Knackstedt LA, Moussawi K, Lalumiere R, Schwendt M, Klugmann M, Kalivas PW (2010) Extinction training after cocaine self-administration induces glutamatergic plasticity to inhibit cocaine seeking. J Neurosci 30: 7984-7992. CrossRef Medline

Kruzich PJ, Congleton KM, See RE (2001) Conditioned reinstatement of drug-seeking behavior with a discrete compound stimulus classically conditioned with intravenous cocaine. Behav Neurosci 115:1086-1092. CrossRef Medline

LeBlanc KH, Ostlund SB, Maidment NT (2012) Pavlovian-to-instrumental transfer in cocaine seeking rats. Behav Neurosci 126:681-689. CrossRef Medline

Lex A, Hauber W (2008) Dopamine D1 and D2 receptors in the nucleus accumbens core and shell mediate Pavlovian-instrumental transfer. Learn Mem 15:483-491. CrossRef Medline

Lovibond PF (1983) Facilitation of instrumental behavior by a Pavlovian appetitive conditioned stimulus. J Exp Psychol Anim Behav Process 9:225-247. CrossRef Medline

Lovic V, Saunders BT, Yager LM, Robinson TE (2011) Rats prone to attribute incentive salience to reward cues are also prone to impulsive action. Behav Brain Res 223:255-261. CrossRef Medline

Marchant NJ, Li X, Shaham Y (2013) Recent developments in animal models of drug relapse. Curr Opin Neurobiol. Advance online publication. doi:10.1016/j.conb.2013.01.003. CrossRef Medline

McClernon FJ, Hutchison KE, Rose JE, Kozink RV (2007) DRD4 VNTR polymorphism is associated with transient fMRI-BOLD responses to smoking cues. Psychopharmacology 194:433-441. CrossRef Medline

Meyer PJ, Lovic V, Saunders BT, Yager LM, Flagel SB, Morrow JD, Robinson TE (2012) Quantifying individual variation in the propensity to attri- 
bute incentive salience to reward cues. PLoS One 7:e38987. CrossRef Medline

Milton AL, Everitt BJ (2010) The psychological and neurochemical mechanisms of drug memory reconsolidation: implications for the treatment of addiction. Eur J Neurosci 31:2308-2319. CrossRef Medline

Munafò MR, Mannie ZN, Cowen PJ, Harmer CJ, McTavish SB (2007) Effects of acute tyrosine depletion on subjective craving and selective processing of smoking-related cues in abstinent cigarette smokers. J Psychopharmacol 21:805-814. CrossRef Medline

Noble EP (2000) Addiction and its reward process through polymorphisms of the $\mathrm{D}_{2}$ dopamine receptor gene: a review. Eur Psychiatry 15:79-89. CrossRef Medline

Ostlund SB, Maidment NT (2012) Dopamine receptor blockade attenuates the general incentive motivational effects of noncontingently delivered rewards and reward-paired cues without affecting their ability to bias action selection. Neuropsychopharmacology 37:508-519. CrossRef Medline

Paolone G, Angelakos CC, Meyer PJ, Robinson TE, Sarter M (2013) Cholinergic control over attention in rats prone to attribute incentive salience to reward cues. J Neurosci 33:8321-8335. CrossRef Medline

Paxinos G, Watson C (2007) The rat brain in stereotaxic coordinates, Ed 6. New York: Academic.

Peck JA, Wercberger R, Kariyeva E, Ranaldi R (2013) Cue-induced resumption of heroin and cocaine seeking in rats using a conflict model of abstinence and relapse. Psychopharmacology (Berl). Advance online publication. doi:10.1007/s00213-013-3069-x. CrossRef Medline

Pelloux Y, Everitt BJ, Dickinson A (2007) Compulsive drug seeking by rats under punishment: effects of drug taking history. Psychopharmacology 194:127-137. CrossRef Medline

Phillips GD, Setzu E, Hitchcott PK (2003) Facilitation of appetitive Pavlovian conditioning by d-amphetamine in the shell, but not the core, of the nucleus accumbens. Behav Neurosci 117:675-684. CrossRef Medline

Preston KL, Vahabzadeh M, Schmittner J, Lin JL, Gorelick DA, Epstein DH (2009) Cocaine craving and use during daily life. Psychopharmacology (Berl) 207:291-301. CrossRef Medline

Rescorla RA (1967) Pavlovian conditioning and its proper control procedures. Psychol Rev 74:71-80. CrossRef Medline

Robbins TW (1976) Relationship between reward-enhancing and stereotypical effects of psychomotor stimulant drugs. Nature 264:57-59. CrossRef Medline

Robinson TE, Berridge KC (1993) The neural basis of drug craving: an incentive-sensitization theory of addiction. Brain Res Rev 18:247-291. CrossRef Medline

Robinson TE, Yager LM, Cogan ES, Saunders BT (2013) On the motivational properties of reward cues: individual differences. Neuropharmacology. Advance online publication. doi:10.1016/j.neuropharm.2013.05.040. CrossRef Medline

Saddoris MP, Stamatakis A, Carelli RM (2011) Neural correlates of Pavlovian-to-instrumental transfer in the nucleus accumbens shell are selectively potentiated following cocaine self-administration. Eur J Neurosci 33:2274-2287. CrossRef Medline

Saunders BT, Robinson TE (2010) A cocaine cue acts as an incentive stimulus in some but not others: implications for addiction. Biol Psychiatry 67:730-736. CrossRef Medline

Saunders BT, Robinson TE (2011) Individual variation in the motivational properties of cocaine. Neuropsychopharmacology 36:1668-1676. CrossRef Medline

Saunders BT, Robinson TE (2012) The role of dopamine in the accumbens core in the expression of Pavlovian-conditioned responses. Eur J Neurosci 36:2521-2532. CrossRef Medline

Saunders BT, Robinson TE (2013) Individual variation in resisting temptation: implications for addiction. Neurosci Biobehav Rev. Advance online publication. doi:10.1016/j.neubiorev.2013.02.008. CrossRef Medline

Schroeder JP, Alisha Epps S, Grice TW, Weinshenker D (2013) The selective dopamine $\beta$-hydroxylase inhibitor nepicastat attenuates multiple aspects of cocaine-seeking behavior. Neuropsychopharmacology. Advance online publication. doi:10.1038/npp.2012.267. CrossRef Medline

Seiden LS, Sabol KE, Ricaurte GA (1993) Amphetamine: effects on catecholamine systems and behavior. Annu Rev Pharmacol Toxicol 33:639-677. CrossRef Medline

Shaham Y, Shalev U, Lu L, De Wit H, Stewart J (2003) The reinstatement model of drug relapse: history, methodology and major findings. Psychopharmacology 168:3-20. CrossRef Medline

Shiffman S, Gwaltney CJ, Balabanis MH, Liu KS, Paty JA, Kassel JD, Hickcox M, Gnys M (2002) Immediate antecedents of cigarette smoking: an analysis from ecological momentary assessment. J Abnorm Psychol 111: 531-545. CrossRef Medline

Simon NW, Mendez IA, Setlow B (2009) Effects of prior amphetamine exposure on approach strategy in appetitive Pavlovian conditioning in rats. Psychopharmacology (Berl) 202:699-709. CrossRef Medline

Sinha R (2013) The clinical neurobiology of drug craving. Curr Opin Neurobiol. Advance online publication. doi:10.1016/j.conb.2013. 05.001. CrossRef Medline

Stewart J, de Wit H, Eikelboom R (1984) Role of unconditioned and conditioned drug effects in the self-administration of opiates and stimulants. Psychol Rev 91:251-268. CrossRef Medline

Stone AA, Shiffman S (1994) Ecological momentary assessment (EMA) in behavorial medicine. Ann Behav Med 16:199-202.

Taylor JR, Robbins TW (1984) Enhanced behavioural control by conditioned reinforcers following microinjections of d-amphetamine into the nucleus accumbens. Psychopharmacology (Berl) 84:405-412. CrossRef Medline

Taylor JR, Robbins TW (1986) 6-Hydroxydopamine lesions of the nucleus accumbens, but not of the caudate nucleus, attenuate enhanced responding with reward-related stimuli produced by intra-accumbens d-amphetamine. Psychopharmacology (Berl) 90:390-397. Medline

Tomie A (1996) Locating reward cue at response manipulandum (CAM) induces symptoms of drug abuse. Neurosci Biobehav Rev 20:505-535. CrossRef Medline

Verbeke G (2009) Linear mixed models for longitudinal data. New York: Springer.

Volkow ND, Wang GJ, Telang F, Fowler JS, Logan J, Childress AR, Jayne M, Ma Y, Wong C (2006) Cocaine cues and dopamine in dorsal striatum: mechanism of craving in cocaine addiction. J Neurosci 26:6583-6588. CrossRef Medline

Wassum KM, Ostlund SB, Balleine BW, Maidment NT (2011) Differential dependence of Pavlovian incentive motivation and instrumental incentive learning processes on dopamine signaling. Learn Mem 18:475-483. CrossRef Medline

Wassum KM, Ostlund SB, Loewinger GC, Maidment NT (2013) Phasic mesolimbic dopamine release tracks reward seeking during expression of pavlovian-to-instrumental transfer. Biol Psychiatry 73:747-755. CrossRef Medline

Wong DF, Kuwabara H, Schretlen DJ, Bonson KR, Zhou Y, Nandi A, Brasić JR, Kimes AS, Maris MA, Kumar A, Contoreggi C, Links J, Ernst M, Rousset O, Zukin S, Grace AA, Lee JS, Rohde C, Jasinski DR, Gjedde A, et al. (2006) Increased occupancy of dopamine receptors in human striatum during cue-elicited cocaine craving. Neuropsychopharmacology 31 : 2716-2727. CrossRef Medline

Wyvell CL, Berridge KC (2000) Intra-accumbens amphetamine increases the conditioned incentive salience of sucrose reward: enhancement of reward "wanting" without enhanced "liking" or response reinforcement. J Neurosci 20:8122-8130. Medline

Wyvell CL, Berridge KC (2001) Incentive sensitization by previous amphetamine exposure: increased cue-triggered "wanting" for sucrose reward. J Neurosci 21:7831-7840. Medline

Yager LM, Robinson TE (2013) A classically conditioned cocaine cue acquires greater control over behavior in rats prone to attribute incentive salience to a food cue. Psychopharmacology 226:217-228. CrossRef Medline 